\title{
Triple-Pulsed Two-Micron Integrated Path Differential Absorption Lidar: A New Active Remote Sensing Capability with Path to SPaCe
}

\author{
Upendra N. Singh*, Tamer F. Refaat, Mulugeta Petros, and Jirong Yu
}

\author{
NASA Langley Research Center, Hampton,VA 23681,USA, *Email: upendra.n.singh@nasa.gov
}

\begin{abstract}
The two-micron wavelength is suitable for monitoring atmospheric water vapor and carbon dioxide, the two most dominant greenhouse gases. Recent advances in 2- $\mu \mathrm{m}$ laser technology paved the way for constructing state-of-the-art lidar transmitters for active remote sensing applications. In this paper, a new triple-pulsed 2$\mu \mathrm{m}$ integrated path differential absorption lidar is presented. This lidar is capable of measuring either two species or single specie with two different weighting functions, simultaneously and independently. Development of this instrument is conducted at NASA Langley Research Center. Instrument scaling for projected future space missions will be discussed.
\end{abstract}

\section{INTRODUCTION}

Water vapor $\left(\mathrm{H}_{2} \mathrm{O}\right)$ and carbon dioxide $\left(\mathrm{CO}_{2}\right)$ are the most dominant greenhouse gases that strongly contribute to the Earth's radiation budget and global warming. Extensive efforts have demonstrated successful $\mathrm{H}_{2} \mathrm{O}$ airborne profiling using the differential absorption lidar (DIAL) technique. In the absence of similar capabilities for $\mathrm{CO}_{2}$ profiling, integrated path differential absorption (IPDA) lidar technique is best suited for measuring the gas weighted average column dry-air volume-mixing ratio $(X)$ [1]. Although it lacks the ranging capability, IPDA provides higher sensitivity measurements that rely on stronger hard target returns versus DIAL, which relies on weaker backscatter signals. Currently NASA is pursuing different IPDA technologies targeting $\mathrm{CO}_{2}$ active remote sensing. Among these technologies, NASA Langley Research Center (LaRC) demonstrated a double-pulse 2- $\mu$ m IPDA for $\mathrm{CO}_{2}$ airborne measurements [2]. Nevertheless, ongoing efforts at LaRC focus on advancing such technology by enhancing the IPDA lidar instrument through triple-pulse operation [3].

A unique airborne triple-pulse, 2- $\mu \mathrm{m}$ IPDA lidar is under development at NASA LaRC. Triple- pulse IPDA lidar operation allows two simultaneous and independent measurements. With wavelength optimization, the instrument can be adjusted to either target $\mathrm{H}_{2} \mathrm{O}$ and $\mathrm{CO}_{2}$ measurements or target $\mathrm{CO}_{2}$ measurements with two different weighting functions. This innovative IPDA lidar is based on a state-of-the-art, efficient, conductively cooled, and injection seeded $2-\mu \mathrm{m}$ triple-pulse laser transmitter under development. For each laser burst, using single pump-pulse, three $2-\mu \mathrm{m}$ pulses are generated and transmitted. These pulses are separated by $200 \mu \mathrm{sec}$, with adjustable pulse-energy and consequently pulsewidth. Wavelength selection, tuning, switching and locking is achieved for each of the three pulses individually. The pulses short-time separation and tuning capabilities results in two simultaneous and independent measurements, respectively. This IPDA lidar instrument will leverage an existing receiver that includes a Newtonian telescope, detection, and data acquisition systems and other low-risk, commercially available components that have been validated through the previous double-pulsed operation. Compared to separate instruments for measuring two species, the triple-pulse IPDA lidar will result in reduced size, mass and power consumption while enhancing the technology for future space-based applications. With additional detection enhancements, the capabilities of this 2$\mu \mathrm{m}$ triple-pulse IPDA lidar is comparable to a $\mathrm{CO}_{2}$ space-based mission proposed by the European Space Agency (ESA), as presented in this paper.

\section{2. $\mathrm{CO}_{2}$ AND $\mathrm{H}_{2} \mathrm{O}$ SENSING}

Water vapor distribution is an essential information for converting the $2-\mu \mathrm{m}$ IPDA measured $\mathrm{CO}_{2}$ optical depth into $X$. In addition, $\mathrm{H}_{2} \mathrm{O}$ interference is a common problem for $\mathrm{CO}_{2}$ remote sensing in the IR spectral region, including the $2-\mu \mathrm{m}$ wavelength. Although, this interference can limit the $\mathrm{CO}_{2}$ measurement sensitivity, it can be significantly reduced by the proper selection of the IPDA operating wavelengths. Triple-pulse 2- 
$\mu \mathrm{m}$ IPDA can further reduce such interference and provide optical depth conversion estimates by measuring $\mathrm{H}_{2} \mathrm{O}$ simultaneously and independently while measuring $\mathrm{CO}_{2}$. This triple-pulse IPDA measurement concept is presented in figure 1 . The figure presents the vertical integrated optical depth spectral profile for $\mathrm{CO}_{2}$ and $\mathrm{H}_{2} \mathrm{O}$ around the $\mathrm{CO}_{2}$ R30 line [1, 4]. The optical depths were derived using HITRAN database for absorption line parameters, assuming Voigt profile, and the US standard atmosphere model for meteorological and molecular profiles. The presented optical depth integration upper limit is based on $8 \mathrm{~km}$ airborne altitude, assuming a small aircraft such as the NASA B-200. Sea level is considered for the lower limit. The $\mathrm{H}_{2} \mathrm{O}$ absorption peak, located at $2050.5322 \mathrm{~nm}$, coincides close to $\mathrm{CO}_{2}$ absorption minima between R30 and R32 lines and away from the R32 peak. The unique tuning and locking capabilities of the 2- $\mu \mathrm{m}$ laser transmitter allow proper selection of the IPDA operating wavelengths. The principle of wavelength selection for this IPDA instrument is demonstrated in the same figure. The $\mathrm{CO}_{2}$ on- and off-line wavelengths are selected around the $\mathrm{R} 30$ line, so that both would have similar $\mathrm{H}_{2} \mathrm{O}$ absorption (lower horizontal line). This minimizes the $\mathrm{H}_{2} \mathrm{O}$ interference on the $\mathrm{CO}_{2}$ measurements. Similarly, the $\mathrm{H}_{2} \mathrm{O}$ on- and off-line wavelengths are selected around the absorption peak such that $\mathrm{CO}_{2}$ interference is minimized on the $\mathrm{H}_{2} \mathrm{O}$ measurement (upper horizontal line). Molecular interference minimization, through wavelength selection, results in independent measurement. However, $\mathrm{CO}_{2}$ and $\mathrm{H}_{2} \mathrm{O}$ measurements share the same wavelength (i.e., the same pulse) for on- and off-line, respectively. This allows achieving simultaneous measurement of both gases with triple pulses rather than quadruple pulses almost independently while avoiding interference from each other. Simultaneous and independent $\mathrm{H}_{2} \mathrm{O}$ and $\mathrm{CO}_{2}$ measurements provide an opportunity to study the two most dominant greenhouse gases variability and interaction through different environmental processes such as photosynthesis and fossil fuel burning.

\section{3. $\mathrm{CO}_{2}$ DOUBLE-WEIGHTING SENSING}

Focusing on the $\mathrm{CO}_{2}$ measurement, figure 2 shows the gas integrated optical depth spectra around the $\mathrm{R} 30$ line. At this location, $\mathrm{H}_{2} \mathrm{O}$ optical

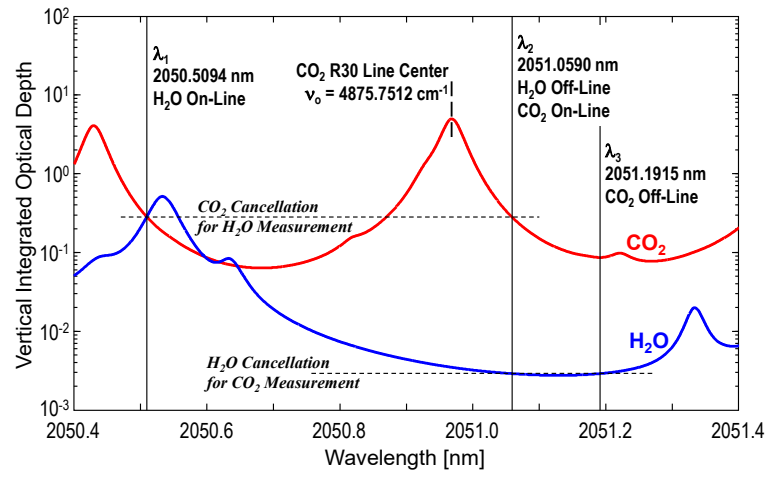

Figure 1. Comparison of the $\mathrm{CO}_{2}$ and $\mathrm{H}_{2} \mathrm{O}$ integrated optical depths derived using the HITRAN data base for line parameters and US Standard atmosphere model for metrological and molecular profiles. Vertical lines mark the instrument selected wavelengths for the three laser pulses, for simultaneous and independent $\mathrm{CO}_{2}$ and $\mathrm{H}_{2} \mathrm{O}$ measurements.

depth, shown on the same figure, is more than order of magnitude lower than $\mathrm{CO}_{2}$, which would contribute negligible interference, particularly in relatively dry environments. In such case, using the same $2-\mu \mathrm{m}$ laser transmitter tuning and locking capabilities allow measuring the gas concentrations using two different weighting functions, simultaneously and independently, as marked by the vertical line in figure 2 and demonstrated in figure 3 . For example, weighting function selection allows measuring $\mathrm{CO}_{2}$ concentration near the surface for studying sources and sinks. With the same off-line and the third pulse tuned to different weighting function $\mathrm{CO}_{2}$ concentration in free troposphere can be targeted simultaneously and independently for studying the gas transport. Other tuning for the weighting function can target the top of the boundary layer for studying $\mathrm{CO}_{2}$ transport between the biosphere and the atmosphere. Switching between $\mathrm{CO}_{2}$ and $\mathrm{H}_{2} \mathrm{O}$ measurement and $\mathrm{CO}_{2}$ double-weighting measurement, and via versa, could be achieved instantaneously through the advance wavelength seeding, tuning then locking during the IPDA lidar airborne operation. Same switching could be even applied between different, pre-defined $\mathrm{CO}_{2}$ weighting to target different sensitivities depending on the geographical location and environment. This unique features would be attractive for space applications. 


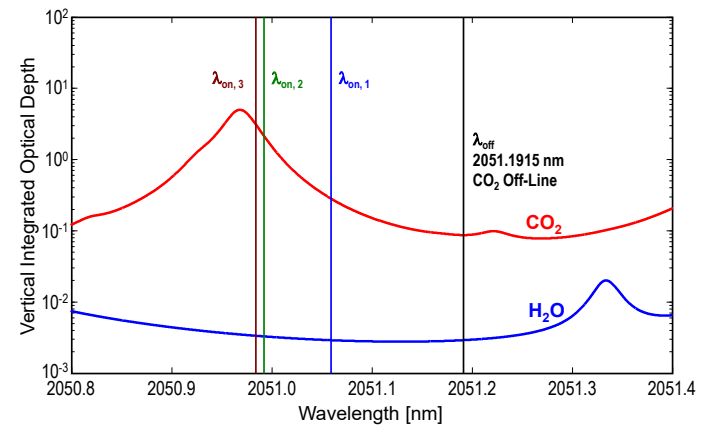

Figure 2. Focusing on the $\mathrm{CO}_{2} \mathrm{R} 30$ line, triplepulse IPDA measurement can target the gas measurement with two different weighting functions, simultaneously and independently. Vertical color coded lines mark selected wavelengths examples for the three laser pulses.

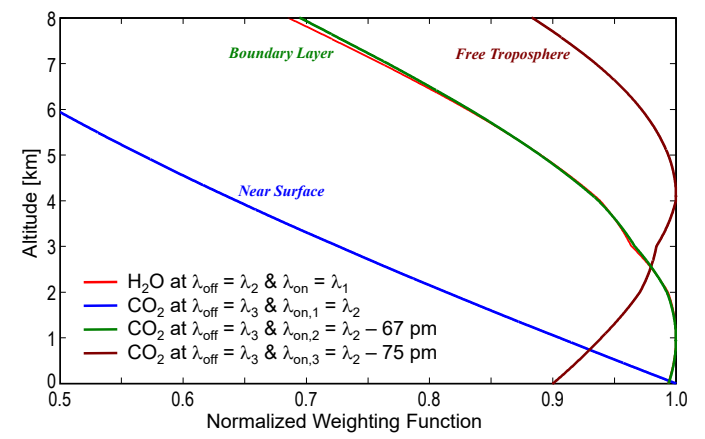

Figure 3. Corresponding color coded peaknormalized pressure-based weighting functions for $\mathrm{H}_{2} \mathrm{O}$ and the selected $\mathrm{CO}_{2}$ on-line wavelength.

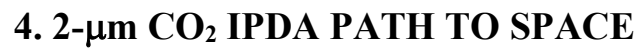

The triple-pulse 2- $\mu \mathrm{m}$ IPDA lidar technology development is enabling for $\mathrm{CO}_{2}$ measurements from space. Recent development of advance single-charge-carrier, $\mathrm{HgCdTe}$ electron avalanche photodiodes (e-APD) indicated a breakthrough in lidar detection technology [5]. These devices are space-qualifiable and were validated for airborne lidar operation at $1.6-\mu \mathrm{m}$. In co-ordination with NASA Earth Science Technology Office (ESTO), NASA LaRC is collaborating with NASA Goddard Space Flight Center (GSFC) to combine their detector with the triple-pulse transmitter towards developing a $2-\mu \mathrm{m}$ triple-pulse IPDA lidar for airborne $\mathrm{CO}_{2}$ measurement. Combining these technologies in a single system will result in a $\mathrm{CO}_{2}$ IPDA lidar instrument that meets or exceed space requirement set by ESA to accomplish the same mission [6].
Table $1 . \mathrm{CO}_{2}$ active remote sensing using the triplepulsed $2-\mu \mathrm{m}$ IPDA, developed at NASA LaRC, compared to ESA space requirements.

\begin{tabular}{lcc}
\hline Transmitter & $\begin{array}{c}\text { NASA } \\
\text { Technology }\end{array}$ & $\begin{array}{c}\text { ESA Space } \\
\text { Requirements }\end{array}$ \\
\cline { 2 - 3 } Laser & Single Laser & Two Lasers \\
Technique & Triple-Pulse & Single-Pulse \\
Cooling & Conductive & Conductive \\
Wavelength & $2.051 \mu \mathrm{m}$ & $2.051 \mu \mathrm{m}$ \\
Pulse Energy & $50 / 15 / 5 \mathrm{~mJ}$ & $40 \& 5 \mathrm{~mJ}$ \\
Repetition Rate & $50 \mathrm{~Hz}$ & $50 \mathrm{~Hz}$ \\
Power & $3.50 \mathrm{~W}$ & $2.25 \mathrm{~W}$ \\
Pulse Width & $30-100-150$ & $50 \mathrm{~ns}$ \\
Optical Efficiency & $5.0 \%$ & $5.0 \%$ \\
Wall-Plug Efficiency & $2.1 \%$ & $>2.0 \%$ \\
Pulse Delay & $200 \mu \mathrm{s}$ & $250 \mu \mathrm{s}$ \\
Transvers Mode & $\mathrm{TEM} 00$ & $\mathrm{TEM} 00$ \\
Longitudinal Mode & Single Mode & Single Mode \\
Pulse Spectral Width & $4-14 \mathrm{MHz}$ & $>60 \mathrm{MHz}$ \\
Beam Quality & 2 & $<2$ \\
Freq. Control Accuracy & $0.3 \mathrm{MHz}$ & $0.2 \mathrm{MHz}$ \\
Seeding Success Rate & 99 & 99 \\
Spectral Purity & $99.9 \%$ & $99.9 \%$ \\
Receiver & & \\
Telescope Diameter & $0.4 \mathrm{~m}$ & $1.2 \mathrm{~m}$ \\
Detector Material & $\mathrm{HgCdTe}$ & --- \\
Detector Structure & $\mathrm{eAPD}$ & $\mathrm{APD}$ \\
Quantum Efficiency & $80 \%$ & $75 \%$ \\
Excess-Noise-Factor & 1.1 & 1.5 \\
Noise-Equivalent-Power & $8 \mathrm{fW} / \mathrm{Hz}{ }^{1 / 2}$ & $100 \mathrm{fW} / \mathrm{Hz}$ \\
\hline & & \\
\hline
\end{tabular}

Table 1 summarizes the projected parameters of the 2- $\mu \mathrm{m}$ triple-pulsed IPDA lidar and compares it to space requirements released by ESA [5]. ESA space requirements were based on a similar $\mathrm{CO}_{2}$ IPDA lidar instrument operating at $2-\mu \mathrm{m}$. ESA objective is to develop future space borne active sensing mission for measuring the dry-air mixing ratio of $\mathrm{CO}_{2}$ throughout the atmosphere with a high accuracy on the ppm level. Table 1 indicates that the triple-pulse $2-\mu \mathrm{m}$ transmitter, in conjunction with the e-APD detector, would result in a $\mathrm{CO}_{2}$ IPDA lidar instrument that meets or exceeds most of the transmitter and detection requirements for space-borne $\mathrm{CO}_{2}$ measurement. The unique triple pulse capability has additional advantages. Having one laser delivering, near simultaneously, three pulses at different frequencies eliminates the complexity and need of three different lasers. This is a significant step towards reducing mass, size and power consumption of the instrument to one third and increasing the efficiency by a factor of three. 
Triple-pulse transmitter eliminates the challenge and complexity in co-aligning and bore-sighting three independent beams. Concurrent to this and supported by ESTO, LaRC is investigating high repetition rate $2-\mu \mathrm{m}$ lasers. Although operating in a single-pulse mode, pulse energy of $40 \mathrm{~mJ}$ was demonstrated with repetition rate as high as 200 $\mathrm{Hz}$. High repetition rate is a desirable transmitter aspect allowing higher average that leads to sensitivity enhancement for space-based lidar. This early development of space qualifiable lasers and air-borne operations will reduce the risk towards future space operation.

Operating from space, adaptive targeting can be easily implemented through the 2-mm triplepulsed IPDA lidar. The unique wavelength switching, tuning and locking capabilities of the instrument allows changing the $\mathrm{CO}_{2}$ weighting and/or include $\mathrm{H}_{2} \mathrm{O}$ measurement instantaneously. For example, this is useful for changing the $\mathrm{CO}_{2}$ measurement weighting function depending on the geographical location and/or the sensing objectives. This would a valuable tool for studying the gas sources, sinks and transport.

\section{CONCLUSIONS}

The societal benefits of better understanding of climate change through identification of global $\mathrm{CO}_{2}$ sources and sinks led to the desired NASA active remote sensing of the gas. The favored solutions for such goal is the IPDA lidar technique. NASA LaRC identified the desired pulsed laser attributes and wavelength regions for $\mathrm{CO}_{2}$ active remote sensors. From foundational work in spectroscopy and modeling to airborne system validation, LaRC demonstrated the capability of $\mathrm{CO}_{2}$ airborne measurement using double-pulse technique at $2-\mu \mathrm{m}$. Extending the technological capabilities, LaRC is developing a unique triple-pulsed 2- $\mu \mathrm{m}$ IPDA lidar. With wavelength optimization, this instrument is capable of achieving two simultaneous and independent measurements. The triple-pulse IPDA can either target $\mathrm{H}_{2} \mathrm{O}$ and $\mathrm{CO}_{2}$ measurements or target $\mathrm{CO}_{2}$ measurements with two different weighting functions. The measurement type and/or weighting could be switched instantaneously during operation. Under NASA ESTO, and with NASA GSFC collaboration, the triple-pulse IPDA lidar capabilities can be further enhanced by including advanced e-APD based detection system. This results in an innovative $\mathrm{CO}_{2}$ IPDA lidar that can meet or exceed space requirement set by ESA for the same objective. This 2- $\mu \mathrm{m}$ triple-pulse IPDA lidar is a possible candidate for future global $\mathrm{CO}_{2}$ active remote sensing from space.

\section{ACKNOWLEDGEMENTS}

This work (ESTO IIP-0013, Principal Investigator: Upendra Singh, LaRC) was funded and supported by NASA Earth Science Technology Office (Program Director: George Komar and Program Manager: Parminder Ghuman).

\section{REFERENCES}

[1] U. Singh, T. Refaat, J. Yu, M. Petros, 2013: Simultaneous and independent measurement of atmospheric water vapor and carbon dioxide using a triple-pulsed, 2-micron airborne IPDA Lidar - a feasibility study, presented at 2013 AGU Fall Meeting, A13C-0213AGU, San Francisco, California.

[2] U. Singh, J. Yu, M. Petros, T. Refaat, R. Remus, J. Fay, K. Reithmaier, 2014: Airborne 2micron double-pulsed integrated path differential absorption lidar for column $\mathrm{CO}_{2}$ measurement", Proc. SPIE 9246, 924602.

[3] T. Refaat, U. Singh, J. Yu, M. Petros, S. Ismail, M. Kavaya, K. Davis, 2015: Evaluation of an airborne triple-pulsed $2 \mu \mathrm{m}$ IPDA lidar for simultaneous and independent atmospheric water vapor and carbon dioxide measurements, Appl. Opt. 54, 1387-1398.

[4] U. Singh, B. Walsh, J. Yu, M. Petros, M. Kavaya, T. Refaat, N. Barnes, 2015: Twenty years of Tm:Ho:YLF and LuLiF laser development for global wind and carbon dioxide active remote sensing, Opt. Mater. Exp. 5, 827-837.

[5] X. Sun, J. Abshire, J. Beck, 2014: HgCdTe eAPD detector arrays with single photon sensitivity for space lidar applications, Proc. of SPIE 9114, 91140K.

[6] P. Ingmann, P. Bensi, Y. Duran, A. Griva, P. Clissold, 2008: A-Scope - advanced space carbon and climate observation of planet earth, ESA Report for Assessment SP-1313/1. 